\title{
PENDEKATAN BUDAYA DALAM HARMONISASI RELASI MUSLIM DAN NON MUSLIM
}

\author{
Surya Adi Sahfutra \\ UIN Sunan Kalijaga Yogyakarta \\ Jl. Marsda Adisucipto (+62-274) 589621 Yogyakarta 55281 \\ E-mail: suryaadisahfutra@gmail.com \\ HP. +6281276014665
}

Abstract: This paper reveals about the life of Islam and its interaction with religious believers in the Turgo Village on the slopes of Merapi. Turgo society living in harmony, which is built on the collective cultural values. Between residents of different religions established communication and interaction are active in various aspects of community life, such as environmental conservation, social and religious interaction, and cultural action undertaken jointly with models of their own religion. Harmony in the society due to cultural aspects are preferred in communication and interaction patterns in the life of a pluralistic rather than the religious aspect. That is, in the public space, culture plays an important role in order to create harmony.

Abstrak: Tulisan ini mengungkap tentang kehidupan Islam dan interaksinya dengan antarumat beragama di Dusun Turgo Lereng Merapi. Masyarakat Turgo hidup harmonis, Keharmonisan dibangun berdasarkan nilai budaya secara kolektif. Antarwarga yang berbeda agama terjalin komunikasi dan interaksi yang aktif dalam berbagai aspek kehidupan warga, misalnya aksi kerjasama pelestarian alam lingkungan, interaksi sosial-keagamaan serta aksi kebudayaan yang dilakukan secara bersama-sama dengan model agamanya masing-masing. Keharmonisan dan kerukunan yang terjadi di masyarakat dikarenakan aspek budaya lebih diutamakan dalam pola komunikasi dan interaksi dalam kehidupan yang pluralistik ketimbang aspek agama. Artinya, dalam ruang publik budaya memainkan peran penting guna terciptanya keharmonisan.

Kata Kunci: Harmoni, Komunikasi, Interaksi, Masyarakat, Islam. 


\section{A. Pendahuluan}

Interaksi yang terjadi dalam proses masuknya agama non-pribumi atau agama pendatang seringkali menimbulkan ekses. Ekses ideologis-paradigmatik, maupun ekses praktis yang terwujud dalam perilaku yang bersumber dari hasil dialektika agama yang datang dengan tradisi yang sudah ada, dalam hal ini kultur masyarakat. Perubahan ini akan menggerus nilai-nilai lama dan digantikan dengan nilai baru pada satu sisi, pada sisi lain adanya kompromi atau akulturasi antara agama dan budaya, setidaknya model-model seperti ini dapat dilihat pada berbagai kultur masyarakat Indonesia. Dalam konteks ini, relasi dapat menimbulkan dua pilihan, yakni agama lebih mendominasi atau justru budaya yang lebih mendominasi.

Pola yang demikian akan mencerminkan nilai sikap dan perilaku masyarakat dengan berbagai ragam ekspresi. Peran serta fungsi agama dan budaya juga sangat penting karena kedua aspek tersebutlah yang memberikan pola hidup dan pola pikir masyarakat. Dari pola yang terbentuk ini akan menentukan bagaimana relasi masyarakat dengan berbagai hal dalam kehidupan sehari-hari, khususnya hubungan dengan umat agama lain dalam menciptakan keharmonisan dan kerukunan.

Agama dengan fungsi transformatifnya akan melakukan perubahan dalam masyarakat, artinya agama akan membuat perubahan bentuk dalam kehidupan masyarakat lama ke dalam bentuk kehidupan masyarakat yang baru (Hendro, 1996: 55-56). Sementara itu, budaya akan senantiasa mengalami pergerakan perubahan. Hal ini sebagai konsekuensi logis dari proses interaksi dan adanya hubungan antarmanusia atau antarkelompok sosial yang memiliki perbedaan kebudayaan (Soerjono, 1987: 172).

Hal ini yang coba peneliti potret dan pahami bagaimana masyarakat Turgo dapat hidup harmonis dengan pemahaman agama masing-masing dan tidak terjadi benturan antarumat beragama yang ada dengan basis kombinasi nilai agama dan budaya yang teraktualisasi dalam perilaku sehari-hari warga.

Tulisan ini mengeksplorasi pola kehidupan masyarakat Turgo berkenaan dengan harmonisasi antarumat beragama dengan beberapa rumusan masalah di antaranya adalah: Bagaimana komunikasi dan interaksi yang terbangun di lingkungan warga Turgo sehingga mampu menciptakan kondisi masyarakat yang harmonis? Bagaimana strategi kebudayaan Islam-Jawa dijadikan oleh masyarakat Turgo dalam menciptakan kehidupan yang harmonis? 


\section{B. Demografis Dusun Turgo}

Bila dilihat dari sejarah awal berdirinya Dusun Turgo, sampai saat ini belum ditemukan referensi yang dapat memastikan sejarah berdirinya. Jika ditelisik dari warga, ada cerita yang secara turun-temurun diceritakan terkait asal-muasal Dusun Turgo. Penamaan Dusun Turgo didasarkan adanya petilasan Syekh Jumadil Kubro, yaitu tempat untuk bertapa yang menjadi situs at au langgar tempat berdoa para wali. Nama Turgo muncul dari kata "Genturke Rogo" yang berarti tempat untuk mengolah batin dan raga.

Secara geografis, Dusun Turgo terletak di ketinggian 1300 mdpl dan berada di lereng Merapi dengan kondisi cuaca dingin. Secara administrasi, Dusun Turgo berada di kawasan Desa Purwobinangun, kecamatan Pakem, Kabupaten Sleman. Luas wilayah Dusun Turgo 138 Ha dengan batas-batas sebagai berikut: sebelah utara berbatasan dengan Hutan Turgo, sebelah timur dengan Kali Boyong, sebelah selatan dengan Dusun Ngepring, sebelah barat dengan Dusun Ngandong. Wilayah Turgo 90\% berupa tanah pekarangan dengan struktur tanah miring dan berpasir, jarak tempuh dari ibukota Kabupaten Sleman berkisar $25 \mathrm{~km}$ dengan waktu tempuh 40 menit. Dari ibukota kecamatan berkisar $10 \mathrm{~km}$ dan waktu tempuh 30 menit. Dari Desa Purwobinangun, Dusun Turgo berada pada radius $7 \mathrm{~km}$ sebelah utara.

Masyarakat Turgo rata-rata berpendidikan SMA, dengan mata pencaharian penduduk mayoritas petani dan peternak, dengan tingkat ekonomi menengah ke bawah. Jumlah penduduk 698 jiwa dengan jumlah 239 kepala keluarga (KK). Komposisi keberagamaan masyarakat Turgo terdiri dari 70\% Islam, 25\% Katolik, dan 5\% Protestan (Suwaji, 20/12/2011 dan data dari kantor desa).

\section{Islam dan Kasih SAyANG}

Dalam masyarakat yang pluralistik, keharmonisan selalu bersanding dengan kerukunan. Hanya dengan sebuah sistem yang baik, maka hal itu dapat dicapai dalam sebuah komunitas masyarakat. Peran serta setiap agama sangat menentukan arah keharmonisan dan kerukunan ini, karena pada dasarnya setiap penganut agama senantiasa mengajarkan kebaikan dan memiliki tujuan perdamaian (Billah, 2006). Oleh karena itu, jika hal ini menjadi perhatian sangat memungkinkan setiap komuntas masyarakat yang plural akan harmonis dan rukun.

Hal lain yang menjadikan agama menunjukkan peran fungsionalnya adalah ketika agama memberikan perubahan pada komunitas itu dan memberikan warna baru dalam masyarakat (Stark \& Glock, 1993: 295). Keyakinan akan 
kebenaran ajaran agama akan mendorong manusia sebagai elemen pokok dalam masyarakat akan bersikap sesuai ajarannya. Tentu hal ini juga akan mempengaruhi pandangan hidup dan budayanya, yang akan terekspresi dalam laku kehidupannya (Irfatul, 2003: 140).

\section{Harmoni Sosial Turgo}

Pluralitas agama dalam komuntas masyarakat Dusun Turgo dalam hal ini menarik untuk diamati dan diteliti, yakni bagaimana masyarakat disana dapat hidup harmonis dan rukun dalam sebuah teritorial yang sama dengan komunitas agama yang berbeda. Kemampuan masyarakat menjalin ukhuwah basyariah (persaudaraan sesama manusia) yang berbeda agama sangat unik dan menarik.

Keharmonisan dalam masyarakat Turgo sebagaimana dijelaskan oleh bapak Nuryadi selaku ketua RT, yaitu:

Masyarakat Dusun Turgo itu punya ikatan persaudaraan yang kuat meskipun berbeda agama; ada Islam, Katolik, Protestan. Karena masyarakatnya sangat kuat memegang nilai-nilai budaya Jawa (ikatan batin kultural) dan kalau masyarakat bercengkerama dan melakukan kerja bakti sosial dan hidup bertetangga masyarakat lebih mengedepankan budayanya. Karena bagi warga, agama adalah urusan pribadi dengan Gusti Allah. Makanya masyarakat dapat hidup harmonis dan rukun lagi (Nuryadi, 20/12/2011).

Secara sederhana, yang dijelaskan oleh Nuryadi tersebut bahwa Dusun Turgo diikat oleh ikatan batin kultural yang sangat melekat di masyarakat, sehingga dalam melakukan komunikasi dan interaksi antarumat beragama mereka selalu mengedepankan aspek budaya dalam berbagai hal. Bagi warga, persoalan agama adalah persoalan pribadi, yang tidak bisa dikedepankan ketika berhadapan dalam komunikasi dan interaksi dengan agama lain. Dengan demikian, ikatan kultural sangat berperan penting dalam terbinanya kerukunan antarumat beragama di Dusun Turgo.

Keharmonisan dan kerukunan ini terbukti hampir selama dua dekade belum pernah terjadi konflik atau keributan antarumat beragama. Ketika ditanya tentang apakah selama menjadi ketua RT, pernah terjadi keributan (konflik) di masyarakat, khususnya antarumat beragama? Nuryadi menjawab:

Selama saya menjadi ketua RT dalam kurun waktu 10 tahun terakhir bahkan 20 tahun yang lalu belum pernah ada keributan atau konflik antarumat beragama di Dusun Turgo. Jika muncul isu atau anggapan yang kurang baik dalam hubungan antarwarga khususnya antarumat beragama maka aparat desa dan pimpinan agama (kaum, imam) akan segera memberikan keterangan dan penjelasan agar warga tidak salah paham dan tidak memperkeruh keadaan (Nuryadi, 20/12/2011). 
Dengan demikian, keharmonisan terjalin tidak hanya peran serta masyarakat yang sadar akan pentingnya kerukunan antarwarga, lebih khusus antarumat beragama, tapi juga peran pemimpin seperti kepala Desa, Lurah, dan pemimpin agama. Lebih tegas lagi apa yang dikemukakan oleh Romo Y. Suyatno pemimpin agama Katolik sangat menarik dalam mengomentari perihal keharmonisan dan kerukunan warga Dusun Turgo:

Karena kesadaran warga akan pentingnya hidup harmonis, baik sesama manusia maupun dengan alam sudah cukup baik, maka peran pemimpin dari masyarakat dan agama hanya sebatas mengawal dan menjaga saja. Kalau boleh dikatakan, tidak begitu berperan aktif lah, hal ini dapat terjadi karena tidak dapat dilepaskan dengan bagaimana konsepsi masyarakat Jawa Turgo dalam memaknai agama. Bagi masyarakat Turgo, agama itu baik jika penganutnya mencerminkan kebaikan kepada sesama manusia maupun dengan alam. Agama itu buruk jika penganutnya mencerminkan keburukan. Agama itu pada dasarnya sama, karena semua agama menyembah Tuhan juga, hanya caranya saja yang berbeda-beda. Selain itu agama tidak mungkin disatukan, jadi yang disatukan yang nilai-nilai kebersamaan dan kemanusiaannya saja yang diikat dan dipererat oleh budaya (Suyatno, 10/12/2011)

Masyarakat yang tradisionalis memiliki kesadaran yang tinggi akan arti pentingnya keharmonisan dan kerukunan dalam sebuah masyarakat yang multiagama. Hal tersebut memungkinkan terjadi karena kondisi geografis Dusun Turgo yang menuntut " kewaspadaan" yang siap siaga seketika ada bencana yang ditimbulkan dari gunung Merapi. Jika lebih ditegaskan lagi bahwa keharmonisan dan kerukunan antarumat beragama di Dusun Turgo merupakan "Suksesi Dialog agama dengan budaya". Fungsionalisasi agama mampu berkompromi dengan nilai-nilai budaya lokal tanpa menggerus dan memarginalkan budaya yang ada dan mampu menciptakan kondisi keberagamaan yang harmonis. Di samping itu, kemampuan setiap agama dan warga berdamai dengan alam dengan pengertian bahwa menjaga kelestarian alam lingkungan demi keberlangsungan hidup sangat penting.

Terkait dengan pandangan keagamaan masyarakat Turgo, baik Islam, Katolik, dan lainnya yang secara luas merupakan representasi masyarakat Jawa, Frans Magnis Suseno mengatakan dengan jelas bahwa orang Jawa membenci dogmatisme, eksklusivisme, fanatisme, kepicikan agama, dan kesombongan. Bukan seakan-akan agama adalah urusan pribadi semata, melainkan orang harus merasakan kemana dan dimana, Tuhan memanggilnya. Dalam budaya Jawa, otonomi orang untuk menemukan sendiri di dasar jiwanya tentang Tuhan sangat dihormati (Frans, 2007: 61). 


\section{Pendekatan Budaya: Interaksi Masyarakat Turgo}

Setiap komunitas memiliki bentuk komunikasi dan interaksi yang berbeda-beda, disesuikan dengan kondisi masyarakat yang ada. Pola komunikasi dan interaksi yang terbentuk menentukan bagaimana bentuk masyarakat itu, khususnya dalam membangun keharmonisan dan kerukunan dalam sebuah masyarakat yang majemuk. Pola komunikasi itu terbentuk dalam ruang-ruang sosial dan keagamaan.

Ruang-ruang sosial tersebut sangat menentukan pola komunikasi sebuah komunitas yang majemuk, karena dalam ruang sosial-budaya yang memungkinkan perbedaan tradisi agama khususnya dapat dipertemukan secara unik dan apik. Komunikasi itu sangat mungkin terjadi dalam beragam bentuk dan pola, hal ini ditegaskan oleh Jalaluddin Rahmat bahwa komunikasi selalu terjadi setiap hari dari bangun tidur hingga tidur lagi. Setiap orang selalu melakukan komunikasi, khususnya dengan orang-orang terdekat dan saling mempengaruhi satu sama lain (Rahmat, 1996).

Dari ruang sosial-budaya yang membentuk interaksi dan komunikasi maka akan terbentuk affective others (Rahmat, 1996: 101-102) yakni orang lain yang dengan mereka seseorang mempunyai ikatan emosional. Dari situ, seseorang membentuk konsep tentang dirinya, senyuman, pujian, penghargaan, dan saling memiliki satu sama lain (Muqawim, 2002: 350).

Masyarakat Dusun Turgo yang plural secara agama mampu membangun pola komunikasi dan interaksi yang unik di ruang sosial-budaya dengan kehidupan masyarakat yang berbeda keyakinan. Komunikasi dan interaksi ant arwarga yang berbeda agama di Dusun Turgo terpola dalam beberapa bentuk sebagai berikut.

\section{Kehidupan Sosial-Keagamaan}

Komunikasi dan interaksi warga Dusun Turgo terjalin dan terbangun dalam kehidupan sosial-kemasyarakatan. Hal ini dapat dipahami karena menurut Durkheim agama merupakan fakta sosial yang dapat diidentifikasi, diamati, serta memiliki kepentingan sosial (Abdullah, 1997: 31). Peran fungsional dari sebuah agama sangat penting guna menjalin komunikasi dan interaksi dalam masyarakat Turgo yang multiagama.

Komunikasi dan interaksi di masyarakat Turgo dalam kehidupan sosialkeagamaan akan muncul ketika ada pelaksanaan acara keagamaan, khususnya Islam dan Katolik. Misalnya, ketika pelaksanaan Salat Idul Fitri, warga yang beragama Katolik turut serta memberikan bantuan moril, seperti menjaga parkir kendaraan, menjaga keamanan rumah, dan saling berkunjung ketika perayaan 
hari raya Idul Fitri. Begitu juga ketika warga yang muslim mengadakan acara pesta atau ada yang meninggal dunia, umat Katolik turut serta membantu secara moril bahkan turut serta mendoakan dengan cara-cara Katolik dan itu diterima oleh umat Islam di Dusun Turgo (Nuryadi, 20/12/2011).

Begitu juga sebaliknya, jika umat Katolik mengadakan ibadah Misa Natal, Paskah, umat Islam turut serta membantu secara moril dan bahkan ibu-ibu yang muslim ikut membantu memasak untuk keperluan ibadah umat Katolik. Tidak hanya ketika ibadah semata, namun setiap ada acara, keterlibatan antarumat beragama cukup terlihat di kalangan masyarakat Turgo (Suwaji, 20/12/2011).

Hal lain yang menjadi penghubung komunikasi dan interaksi antarwarga yang berbeda agama dalam kehidupan sosial terjadi dalam bentuk aktivitas sosial seperti gotong-royong. Dalam pembangunan rumah warga atau tempat ibadah, antarwarga saling membantu tanpa membedakan agamanya. Masyarakat menghayati bahwa tindakan-tindakan dalam ruang sosial didasarkan pada asumsi-asumsi dan tindakan kultur masyarakat (Bernard, 2000: 17).

Di ruang publik pembicaraan persoalan agama sangat jarang terjadi di lingkungan masyarakat Turgo. Hal ini dikarenakan pandangan mereka bahwa setiap agama adalah jalan menuju Tuhan, dan agama adalah persoalan pribadi. Agama itu baik, kalau perilaku penganutnya juga baik. Pembicaraan warga lebih sering pada persoalan lingkungan, budaya, dan persoalan ekonomi (Nuryadi, 20/12/2011). Pola komunikasi dan interaksi seperti ini yang menjadikan masyarakat Turgo memiliki ikatan emosional yang kuat dalam membina keharmonisan dan kerukunan.

\section{Kehidupan Sosial-Budaya}

Interaksi dan komunikasi di masyarakat Turgo juga terjadi dalam kehidupan sosial-budaya. Maksudnya, warga yang berbeda agama diikat oleh satu budaya yang sama memudahkan untuk berinteraksi dan bekomunikasi di ruang sosial-budaya.

Ikat an batin kultur Jawa sangat berperan bagi setiap agama yang ada di Dusun Turgo, khususnya Islam dan Katolik. Bentuk komunikasi dan interaksi dalam ruang sosial-budaya terlihat dalam bentuk ekspresi kebudayaan, seperti seni yang begitu menonjol. Aktivitas seni tersebut muncul sebagai bentuk kebersamaan dalam perbedaan agama, munculnya grup seni seperti Laras Madyo di kalangan muslim Turgo dan Seniloka di kalangan Katolik Turgo. Uniknya proses ketika seni itu dipertunjukkan, baik dalam proses latihan maupun pementasan, kedua kelompok seni yang bernuansa agama ini selalu tampil bersama. Bedanya dari kedua kelompok ini terletak pada muatan pesan 
syairnya saja, kalau Seniloka bermuatan syair puji-pujian Katolik dan Laras Madyo bermuatan shalawat Nabi dalam bahasa Jawa. Kalau Laras Madyo latihan atau pentas, maka Seniloka yang memainkan gamelan dan alat musik lainnya, begitu juga sebaliknya ketika Laras Madyo latihan atau pentas maka Seniloka yang memainkan alat musiknya (Bambang, 20/12/2011).

\section{E. Simpulan}

Dialog agama dengan budaya dapat menjadi harmoni antarumat beragama manakala: Pertama, warga memiliki pandangan filosofis yang cukup kuat yang bersumber dari kombinasi nilai-nilai kearifan lokal (local wisdom) dengan nilainilai agama yang mereka pahami. Kedua, Kemampuan masyarakat dalam mengamalkan nilai tradisi budaya yang menjadi nilai sumber pemahaman mampu memfilter derasnya arus modernisasi di segala lini kehidupan yang menuntut adanya perubahan paradigma berpikir seseorang. Ketiga, kemudahan masyarakat dalam membina keharmonisan dan kerukunan antarumat beragama oleh etnis Jawa dan masih memegang teguh budaya adat dan dunia kosmologis. Keempat, menghormati adanya keberagaman dalam memilih agama sebagai keyakinan sehingga budaya yang menyatukan mereka.

\section{Daftar Pustaka}

Abdullah, Amin dkk. 2002. Tafsir Baru Studi Islam dalam Era Multi Kultural. Yogyakarta: IAIN Sunan Kalijaga dan Kurnia Kalam Semesta.

Adeney, Bernard T. 2000. Etika Sosial Lintas Budaya, Terj. Ioanes Rakhmat. Yogyakarta: Kanisius.

Billah, MM. 2006. dalam pengantar buku Agama dan Hak Asasi Manusia, terj. Ahmad Suedy dan Elgar Sarapung. Yogyakarta: Interfidei.

Hendropuspito. 1996. Sosiologi Agama. Yogyakarta: Kanisius.

Hidayah, Irfatul. 2003. “Agama dan Budaya Lokal: Peran Agama dalam Proses Marginalisasi Budaya Lokal” dalam Jurnal Religi vol. II. 2003.

Rahmat, Jalaluddin. 1996. Psikologi Komunikasi. Bandung: Remaja Rosdakarya.

Syamsudi, Abdullah. 1997. Agama dan Masyarakat; Pendekatan Sosiologi Agama. Jakarta: Logos Wacana Ilmu.

Suseno, Frans Magnis. 2007. "Bisakah Agama-Agama Terbuka Satu Sama Lain?” dalam Meretas Jalan Teologi Agama-Agama di Indonesia; Theologia Religionum. Jakarta: Gunung Mulia. 
Stark R dan C.Y. Glock. 1993. "Dimensi-dimensi Keberagamaan" dalam Agama dalam Analisa dan Interpretasi Sosiologis. Jakarta: Raja Grafindo Persada. Soekanto, Soerjono. 1987. Sosiologi Suatu Pengantar. Jakarta: Rajawali Pers. Wawancara dengan Suwaji (52) ketua RW dan guru agama Katolik Dusun Turgo.

Wawancara dengan Nuryadi (45) Ketua RT dan Najir Masjid Dusun Turgo. Wawancara dengan Bambang (41) warga biasa.

Wawancara dengan Romo Y. Suyatno Hadiatmaja (53) Pastor agama Katolik. 